Article

\title{
Stem Branching of Cycad Plants Informs Horticulture and Conservation Decisions
}

\author{
Thomas E. Marler ${ }^{1, *(1)}$ and Michael Calonje ${ }^{2(1)}$ \\ 1 Western Pacific Tropical Research Center, University of Guam, UOG Station, Mangilao, Guam 96923, USA \\ 2 Montgomery Botanical Center, 11901 Old Cutler Road, Coral Gables, Florida, FL 33156, USA; \\ michaelc@montgomerybotanical.org \\ * Correspondence: marler.uog@gmail.com; Tel.: +1-671-735-2100
}

Received: 22 September 2020; Accepted: 6 October 2020; Published: 8 October 2020

\begin{abstract}
The number of branches in male and female plants of Cycas micronesica K.D. Hill, Cycas edentata de Laub., Cycas wadei Merr., and Zamia encephalartoides D.W. Stev. were counted in Guam, Philippines, and Colombia, to confirm earlier reports that female plants develop fewer branches than males. Cycas plants produce determinate male strobili and indeterminate female strobili, but Zamia plants produce determinate strobili for both sexes. More than $80 \%$ of the female trees for each of the Cycas species were unbranched with a single stem, but more than $80 \%$ of the male trees exhibited two or more branches. The mean number of branches on male plants was more than double that of female plants. The number of branches of the Zamia male plants was almost triple that of female plants. Moreover, the Zamia plants produced 2.8-fold greater numbers of branches than the mean of the Cycas plants. Most of Guam's unsexed C. micronesica trees in 2004 were unbranched, but after 15 years of damage from non-native insect herbivores, most of the remaining live trees in 2020 contained three or more branches. The results confirm that male Cycas and Zamia plants produce more branches than female plants and suggest cycad species with determinate female strobili produce more branches on female plants than species with indeterminate female strobili. Our results indicate that the years of plant mortality on Guam due to non-native insect herbivores have selectively killed more female $C$. micronesica trees. Horticulture and conservation decisions may be improved with this sexual dimorphism knowledge.
\end{abstract}

Keywords: Cycas; determinate growth; dichotomous branch; isotomous branch; sexual dimorphism; Zamia

\section{Introduction}

Cycads are dioecious gymnosperms that are of horticultural and conservation interest [1,2], and are widely considered the most threatened plant group worldwide [3] primarily due to habitat destruction and the unsustainable trade of wild-collected plants. The unsustainable harvesting of cycads is a major concern at the local level but also internationally, where their trade is regulated by the Convention on International Trade in Endangered Species of Wild Fauna and Flora (CITES) $[4,5]$. Adaptive management of threatened cycad species requires the co-production of knowledge during conservation projects [6]. During horticultural projects in cultivated settings and biology or ecology projects in habitat, research results may provide crucial information for improving management decisions [7].

In wild cycad populations, only a certain proportion of plants may exhibit strobili at a given time. Consequently, most short-term field studies of these populations record sex ratio estimates that represent only what was observable at the time of fieldwork. This estimate is variously known as the coning [8], operational [9], or observed sex ratio [10], and it may differ greatly from the true genotypic 
sex ratio of the population and may vary widely depending on the time of year when observations were made. Therefore, the development of any protocol that would inform how to improve on the methods for determining the sex of cycads may improve decision-making.

Three publications indicated the use of stem branching of a cycad plant might be useful as secondary sex characteristics [11] for predicting sex of a plant. First, Ornduff [12] followed a cultivated group of Zamia integrifolia L.f. plants in Florida for $9 \mathrm{y}$ to determine growth traits. The male plants produced an average of 5.7 branches per plant and the female plants produced 2.7 branches per plant. Male plants began producing cones at an earlier age and produced more cones throughout the observational period than female plants. These reproductive behavior differences were discussed as the probable cause of increased branching in male plants.

Second, Norstog and Nicholls [1] (p. 141) studied a fifty-year-old planting of Z. integrifolia and found marked sexual dimorphism in the cultivated cohort, with the males carrying more branches, more cones, and more leaves than female plants. The males held an average of 27 branches per plant whereas the females held an average of 8 branches per plant. The more frequent branching in male plants was attributed to the males experiencing more frequent coning events and producing more cones per reproductive episode than the female plants.

Third, Niklas and Marler [13] determined the branching traits of 483 C. micronesica adult plants in four research locations in Guam. The male trees exhibited a mean of 3.4 branches per tree and the female trees exhibited a mean of 1.5 branches per tree. The difference in reproductive behavior of male and female Cycas plants was discussed as the probable cause of increased branching in male trees.

Throughout our field work we recorded the number of stem apices on plants within numerous in situ populations as part of the plant metrics obtained to more fully understand the biology of several species. Our objectives herein were to look closely at these data to more fully understand branching behavior of four cycad species. Moreover, we observed branching behavior of C. micronesica before the invasions of several non-native insect herbivore species that have led to $96 \%$ mortality of Guam's population [14]. We exploited this phenomenon to look closely at branching behavior of the tree population that has survived the biological threats. Finally, we explore how this knowledge may improve horticultural and conservation decisions.

\section{Materials and Methods}

We collected data from numerous areas of occupancy for four cycad species in Colombia, Guam, and Philippines. These data included sympatric species, plant height and basal stem diameter, number of branches, number of leaves per plant and leaflets per leaf, length of petiole and rachis, and size of strobili if present. For the purpose of this study, we focused on the number of stem apices on each plant that we could identify as male or female. The general appearance of male and female Cycas trees in Guam and Philippines contrasted sharply with the appearance of male and female Z. encephalartoides plants in Colombia, the latter species had much shorter stems with a higher prevalence of stem branching (Figure 1). 

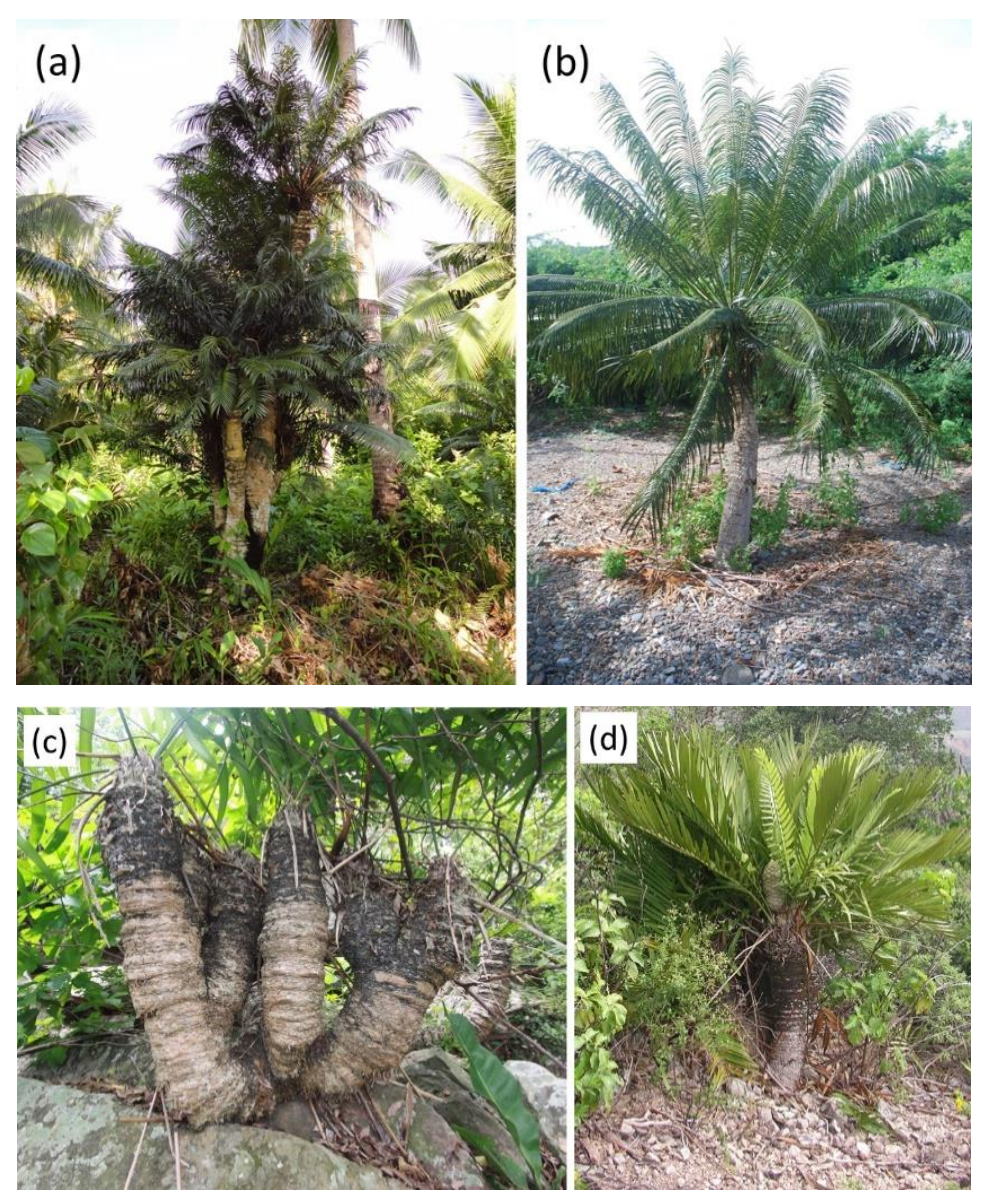

Figure 1. The appearance of Cycas plants in Guam and Philippines: (a) male; (b) female. The appearance of Zamia plants in Colombia: (c) male; (d) female.

\subsection{Cycas micronesica}

The observations on C. micronesica trees were conducted in 2004 in Guam. Ten areas of occupancy throughout Guam were used for biochemistry studies designed to determine the biological and habitat factors that influenced neurotoxin concentrations in seeds. The plant traits were recorded in conjunction with these methods. Several non-native insect herbivore species invaded Guam during this time period, but their entry into our study sites occurred in 2005. Therefore, the 2004 data captured the population traits prior to any non-native insect herbivore damage. The number of branches on every tree that was identified as male or female was recorded. These data were combined to define traits of 1041 male and 754 female trees.

\subsection{Cycas edentata}

We observed 23 areas of occupancy of $C$. edentata among numerous islands within a latitudinal gradient of $9^{\circ} 10.655^{\prime}-13^{\circ} 32.145^{\prime} \mathrm{N}$ and longitudinal gradient of $119^{\circ} 52.788^{\prime}-126^{\circ} 7.122^{\prime} \mathrm{E}$. The field work was conducted from August 2008 to March 2019. These data were combined to obtain measurements on 178 male and 234 female trees.

\subsection{Cycas wadei}

The only known endemic population of C. wadei on Culion Island was observed in March 2019 to obtain measurements on 104 male and 153 female trees. 


\subsection{Zamia encephalartoides}

A single large grouping of Z. encephalartoides, restricted to a single plateau and consisting of 287 adult-sized individuals was studied in Santander, Colombia in February 2009 as part of a conservation survey for this species [15]. This population consisted of monopodial individuals or clumps containing up to 40 stems. As the stems of this cycad species may be partly subterranean and some branching may occur underground, it was sometimes difficult to ascertain with certainty whether clumps of stems belonged to the same individual plants. For the purpose of this study, only clumps exclusively containing strobili of a single sex and where all stems exhibited similar phenological stages were counted as individual plants. As the species occurs in a hot and dry environment, cone remnants can remain on plants for several months, allowing the sexual identity to be determined for over $80 \%$ of the observed plants. Measurements were obtained from 143 male and 88 female plants.

\subsection{Unbiased Demography of Cycas micronesica}

The methods described in the previous sub-sections employed biased methods where sexual identity of a plant was verified prior to collection of data. These methods did not allow an understanding of the branch patterns of the entire population, including plants that were mature in stature but exhibited no evidence of a strobilus. Therefore, we collected data from three high density C. micronesica localities with $900+$ mature plants per ha along the east coast of Guam in January $2004\left(13^{\circ} 25.674^{\prime}-13^{\circ} 29.847^{\prime}\right)$. We used four $4 \times 100 \mathrm{~m}$ transects per locality and observed every plant greater than $100 \mathrm{~cm}$ in height and recorded the number of branches. A total of 432 mature plants were observed. We returned to these same localities to repeat the measurements in January 2020. By this time the density was less than 200 plants per ha. We repeated the methods with $4 \times 100 \mathrm{~m}$ transects, but because of the plant density we increased the number of transects in each locality until we reached $\approx 150$ plants per locality. A total of 456 mature plants were observed.

\subsection{Analyses}

The male versus female branch number data for each species were analyzed separately. The data did not meet parametric prerequisites, so we used the Mann-Whitney $U$ test to determine significance (SPSS Statistics, IBM Corp., Armonk, NY, USA).

\section{Results}

\subsection{Cycas micronesica}

Most of the male C. micronesica trees contained two branches, accounting for about $70 \%$ of the trees (Figure 2a). The male trees that were unbranched accounted for about $10 \%$ of the trees, and the trees with three or more branches accounted for the remainder of the male trees. In contrast, the unbranched female C. micronesica trees accounted for about $80 \%$ of the population. The mean number of branches for male trees was almost double that for female trees (Table 1).

Table 1. The influence of sex on stem branching of four cycad species. Significance determined by the Mann-Whitney $U$ test. Means \pm standard error.

\begin{tabular}{ccccccc}
\hline Species & Sex & $N$ & Range & Mean & $U$ & $P$ \\
\hline Cycas micronesica & Male & 1041 & $1-12$ & $2.52 \pm 0.06$ & & \\
& Female & 754 & $1-8$ & $1.36 \pm 0.04$ & 167,130 & $<0.001$ \\
Cycas wadei & Male & 104 & $1-7$ & $2.55 \pm 0.12$ & & \\
& Female & 153 & $1-3$ & $1.12 \pm 0.04$ & 1779 & $<0.001$ \\
Cycas edentata & Male & 178 & $1-10$ & $3.03 \pm 0.12$ & & \\
& Female & 234 & $1-2$ & $1.07 \pm 0.02$ & 2698 & $<0.001$ \\
Zamia encephalartoides & Male & 143 & $1-40$ & $8.14 \pm 0.61$ & & \\
& Female & 88 & $1-18$ & $2.83 \pm 0.31$ & 2649 & $<0.001$ \\
\hline
\end{tabular}



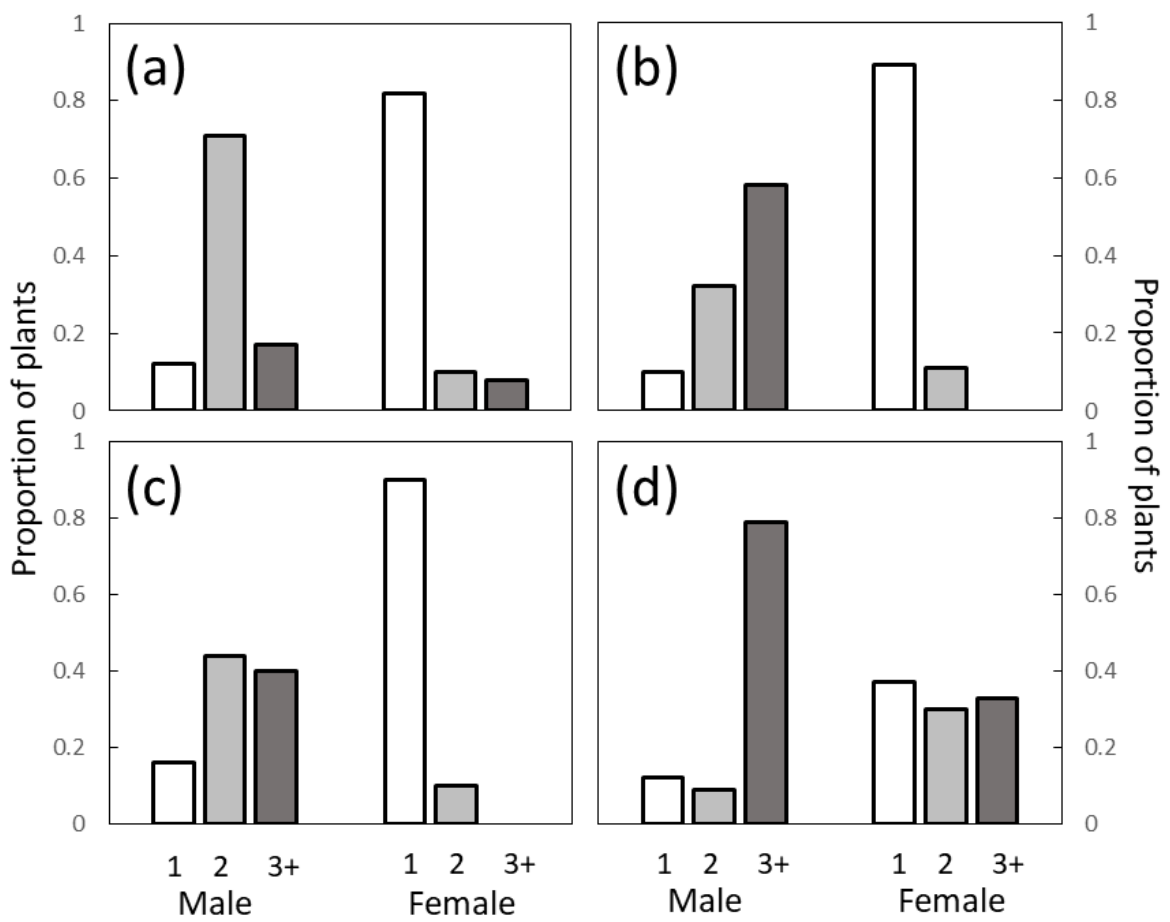

Figure 2. The influence of sex on the proportion of plants with 1, 2 or $3+$ branches. (a) Cycas micronesica; (b) Cycas wadei; (c) Cycas edentata; (d) Zamia encephalartoides.

\subsection{Cycas wadei}

The number of male $C$. wadei trees with two branches and the number with three or more branches each accounted for about $40 \%$ of the trees (Figure $2 b$ ). Almost $20 \%$ of the male trees were monopodial. In contrast, the unbranched female $C$. wadei trees accounted for about $90 \%$ of the population, with the remainder of the trees producing two branches. The mean number of branches for male trees was 2.3-fold greater than that for female trees (Table 1).

\subsection{Cycas edentata}

The number of male C. edentata trees with three or more branches accounted for about $60 \%$ of the trees (Figure 2c). The male trees that were unbranched accounted for about $10 \%$ of the trees, and the trees with two branches accounted for the remainder of the trees. The female $C$. edentata trees exhibited branch proportions that were similar to those of $C$. wadei. The mean number of branches for male trees was 2.8 -fold greater than that for female trees (Table 1).

\subsection{Zamia encephalartoides}

The Z. encephalartoides plants generally exhibited many more branches than any of the Cycas trees. About $80 \%$ of the male plants exhibited three or more branches (Figure $2 \mathrm{~d}$ ). The remainder of male plants were split evenly between unbranched and two-branched individuals. The female Z. encephalartoides plants were fairly evenly split among plants with one, two, or more than two branches. The mean number of branches for male Z. encephalartoides plants was more than two times greater than the mean of the three Cycas species and was almost triple that of female Z. encephalartoides plants (Table 1).

\subsection{Unbiased Demography}

Surveys of every C. micronesica tree in excess of $100 \mathrm{~cm}$ in height from Guam's high-density localities indicated more than $60 \%$ of the 2004 trees were unbranched (Figure 3). About $20 \%$ of these pre-invasion trees exhibited two branches, and about $20 \%$ exhibited three or more branches. 
The widespread mortality that occurred prior to 2020 preferentially targeted unbranched trees, as the 2020 observations indicated less than $10 \%$ of the population was unbranched. The percentage of trees with two branches remained at about $20 \%$ of the population, but trees with three or more branches accounted for about $75 \%$ of the population. Therefore, a 7.6 -fold decrease in unbranched trees accompanied a 4-fold increase in trees with more than two branches during the changes between our two years of observation.

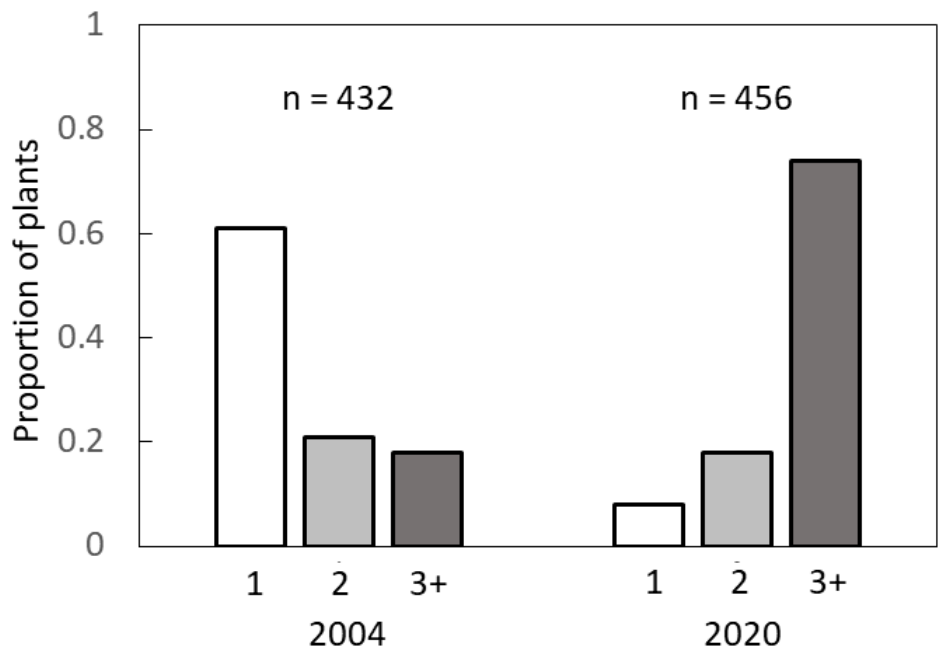

Figure 3. The influence of year on the proportion of Cycas micronesica plants with 1, 2 or $3+$ branches. $\mathrm{n}$ represents the total number of trees in each census.

\section{Discussion}

The higher propensity for branching in male versus female cycad plants reported for cultivated Z. integrifolia [2,12] was also documented for in situ populations of Cycas micronesica [13]. The present study confirms these findings with robust in situ data sets of three Cycas species and one Zamia species. We believe the higher branch number found in male plants of the species studied may be the consequence of isotomous branching associated with the more frequent coning of male cycad plants $[12,16]$. Vegetative branching in cycads occurs via two known mechanisms: isotomous branching of the shoot apex or adventitious branching associated with damaged stem regions or leaf bases [17]. Adventitious branching is the most common form of branching in cycads, occurring in the ten living cycad genera and producing the offsets (known as suckers or pups) that are typically used for vegetative propagation of cycads. Isotomous vegetative branching, where the shoot apex divides dichotomously at the stem axis to form two equal branches, appears to be much rarer in cycads and has only been reported in Cycas, Dioon, and Zamia [1,12,17-19]. However, another dichotomous branching process, termed anisotomous branching [17] occurs in cycad genera that produce terminal strobili.

In anisotomous branching, the original apex dichotomizes and produces a fertile apex that will develop a cone (or set of cones) and another apex that goes dormant and resumes vegetative growth after the strobili mature [17]. Anisotomous branching is detectable in the anatomy of cycads stems by the presence of dome-like profiles of vascular tissue known as cone domes [1] (p. 45) but is not readily apparent externally because the vegetative apex resumes upward growth of the stem in a seemingly continuous fashion.

All cycad genera, with the exception of members of the Tribe Encephalartae (sensu [20]) produce terminal cones and therefore undergo anisotomous branching. In Encephalartae, comprised of the three related genera Encephalartos Lehm., Macrozamia Miq., and Lepidozamia Regel [21], cones are produced to the side of the vegetative apex with no associated apex dichotomy [22]. In Cycas, anisotomous branching is restricted to male plants, as female plants produce indeterminate crowns of individual sporophylls (Figure 4) that are produced similarly and alternately with crowns of leaves $[23,24]$. 


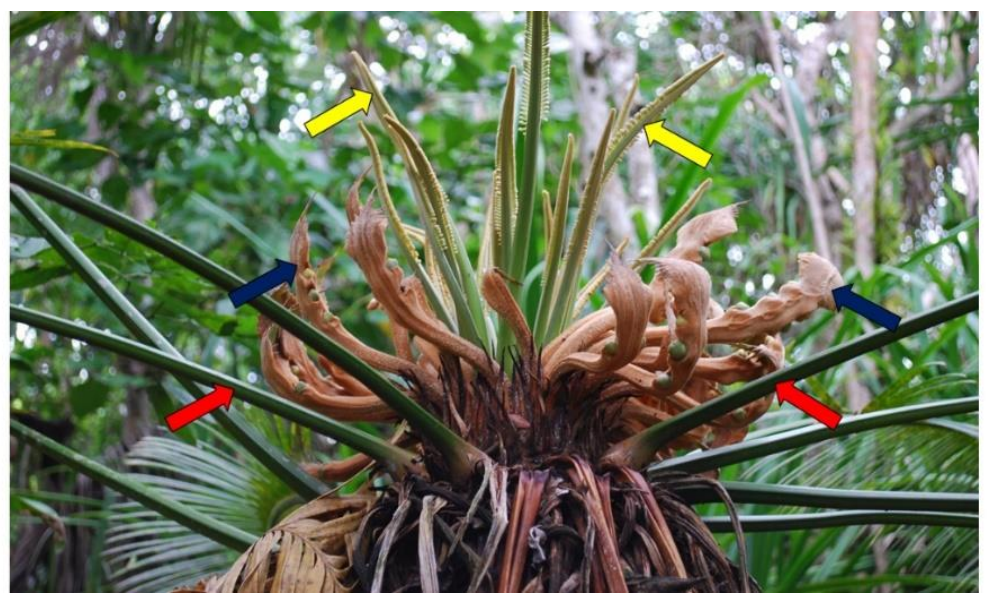

Figure 4. The reproductive behavior of a female Cycas plant produces a megastrobilus that is not determinate. Each sporophyll is an obvious homolog of the pinnate compound leaf. Sporophylls from a megastrobilus (blue arrows) separate the antecedent (red arrows) and subsequent (yellow arrows) leaf growth events.

Multiple studies have associated coning events with vegetative branching, suggesting a close association between anisotomous and isotomous branching. Gorelick [19] reported isotomous branching in Zamia furfuracea L.f. immediately following a coning event. In this case, the vegetative branches occurred on both sides of the cone axis with both branches producing simultaneous vegetative flushes. Ornduff [12] observed branching was closely associated with cone production in a cultivated cohort of $Z$. integrifolia. He found a significantly higher number of branches were produced by male plants and attributed this phenomenon to the male plants experiencing more coning events due to their reproduction starting at an earlier age than the females. Similarly, in a cultivated group of Z. integrifolia plants of similar age, Norstog and Nicholls [1] (p. 141) found a significantly larger number of branches on males than females. This phenomenon was attributed to increased apex subdivisions due to their more frequent cone production. Additionally, male plants were generally more robust and produced more leaves than females.

The process of isotomous vegetative branching associated with a coning event is illustrated in male Cycas micronesica (Figure 5). In a similar manner as described by Gorelick [19] with Z. furfuracea, following the production of a terminal cone, two branches of similar size are formed at either side of the cone axis and produce vegetative flushes simultaneously. In this study, isotomous vegetative branching was observed only on male Cycas plants, but on both sexes of Zamia.

The branching behaviors of the three Cycas species were remarkably similar, with less than $20 \%$ of male trees and more than $80 \%$ of the female trees exhibiting unbranched trunks. Most female trees were unbranched for all three Cycas species, but the mean and maximum number of branches observed in female $C$. micronesica trees exceeded those in the other two species. We note two factors that may explain these differences. First, the differences could be due to inter-specific genetic differences where C. micronesica is more prone to branching. The addition of many more Cycas species to this research agenda would aid in understanding the role of genetics on branching of female trees. Second, the greater branching from Guam's trees may be due to greater tropical cyclone (TC) activity. The Philippine and Guam habitats are within the most active TC basin worldwide [25]. Guam's propensity for TC occurrence must be considered when making horticultural decisions for perennial crops [26]. A major TC in 1997 caused an estimated 10\% of Guam's C. micronesica population to become decapitated with the entire stem apex snapped off [27]. Guam's trees that suffer this form of damage during TCs develop numerous adventitious buds at positions on the stem that are proximal to the break ([28], Figure 1). After almost two years of regrowth, the trees that withstood the 1997 TC with intact apices exhibited only two vegetative growth events, but the decapitated trees exhibited as many as 25 vegetative growth events over the experimental period as a result of the numerous adventitious 
branches [29]. Observations since the invasions of several non-native insect herbivores indicate this new biotic threat has weakened the C. micronesica stems such that they are more vulnerable to TC damage [30]. This was confirmed during a 2015 TC when damage to the C. micronesica population was greater than expected based on historical observations of damage [31]. The third possible explanation for the greater number of apices for $C$. micronesica than for the other two Cycas species could be an interaction of genetic differences and TC propensity. This could be tested by observing branching patterns of mature specimens of the three Cycas species in a common garden setting.
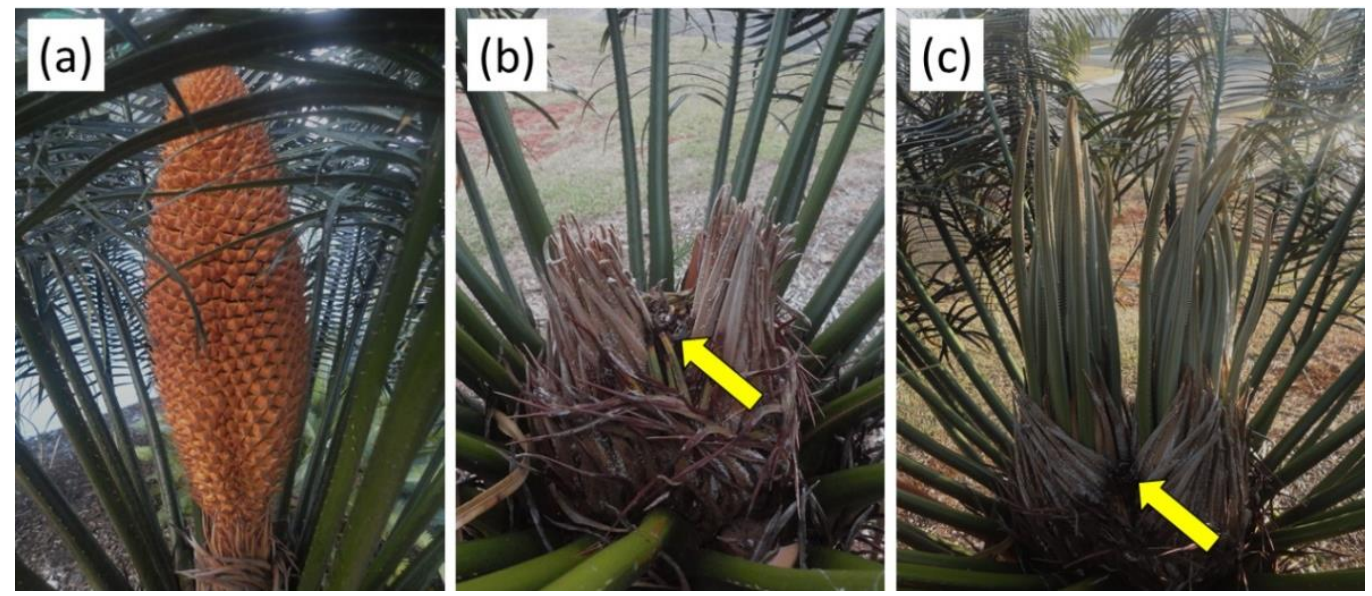

Figure 5. The reproductive behavior of a male Cycas plant. (a) July 2019 microstrobilus is determinate and terminates the stem growth; (b) the appearance of two adventitious apices becomes apparent five months later; (c) resumption of stem growth is apparent seven months after the microstrobilus. Yellow arrows point to the base of the antecedent microstrobilus.

\subsection{Refinements}

A look at the gestalt appearance of the entire branched Cycas canopy offers more refined diagnostics by using topology. The first tenet that can be employed to interpret a tree's canopy is that trees with multiple sites of bifurcation are likely males. Consider two model trees with five apices. One tree exhibits four bifurcation events leading to four stratified dichotomous branching components of the canopy (Figure 6a). The second tree exhibits five stems that converge to unite at one stratum of the basal stem (Figure 6b). The first tree is likely a male tree because of the multiple examples of dichotomous branching. The second tree could be either sex because the branching connotes adventitious branching in response to a mechanical injury at the stratum of the manifold branching. The number of $C$. micronesica trees that develop a canopy similar to Figure $6 \mathrm{~b}$ may increase in the future due to the issues described in Section 4.1. The stems that have been weakened by non-native insect herbivory may break more often in future TCs such that more trees on average develop regrowth with multiple adventitious branches emerging from one stratum.

A second tenet that may aid in interpretation of branching is that the isotomous branching following a determinate strobilus generates two branches of a similar size, as can be seen in Figures 1c and 6a. If a cycad stem reveals branching into two stems, and one secondary stem is much larger than the other second secondary stem, this is not likely the result of a post-strobilus bifurcation event. Sometimes, two equal sized branches may develop from adventitious branching after an injury, a phenomenon referred to as pseudoisotomous branching by Stevenson [17]. Pseudoisotomous branching is distinguishable macromorphologically from isotomous branching. In isotomous branching, the leaf base pattern is continuous between the stem and the branches and no constriction is observed at the base of the branches, whereas in pseudoisotomous branching, the leaf base pattern is discontinuous and constriction is observed at the base of the branches [17]. These tenets may be most easily condensed to the simple rule that multiple examples of dichotomous branching on a Cycas tree likely signifies 
a male tree and unbranched stems likely signify a female tree. Our observations of Cycas trees in the field suggest that isotomous branching is most common in male plants, and that it is either very rare or inexistent in female plants. In contrast, isotomous branching was observed on both sexes in Z. encephalartoides, suggesting that this type of branching may be associated with the capability of producing terminal cones.

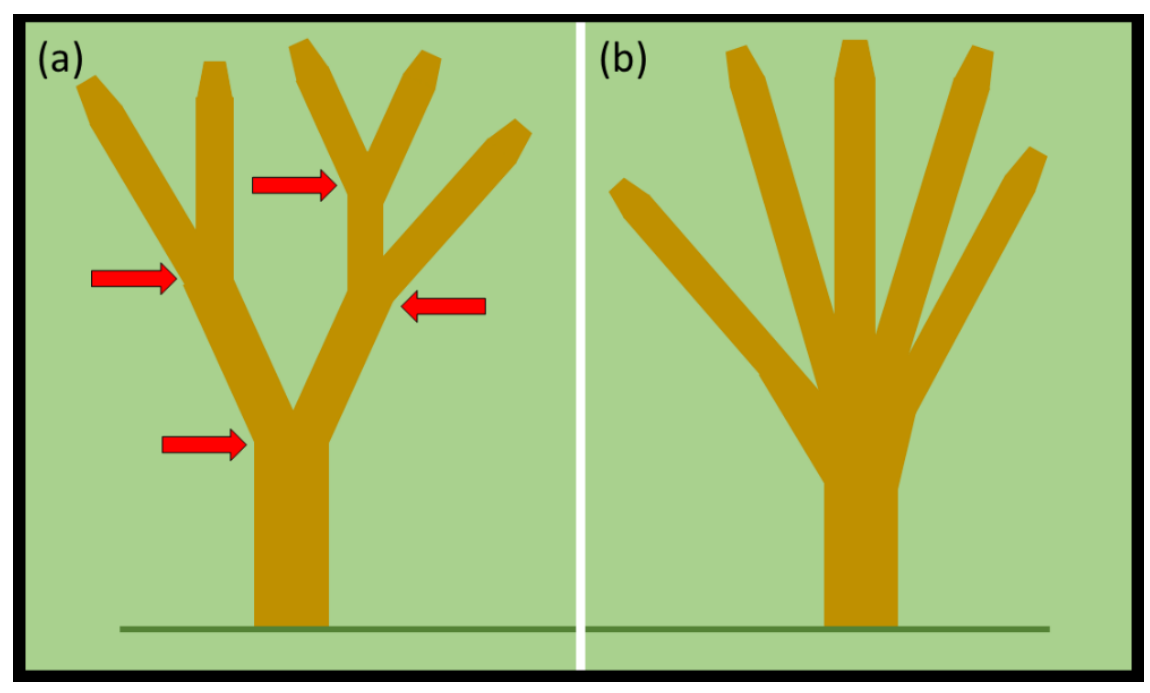

Figure 6. Two approaches for producing branches on a cycad plant. (a) Four bifurcations (red arrows) at different strata generate five apices; (b) five branches emerge from one stratum.

\subsection{Horticulture and Conservation}

Our unambiguous results revealing sexual dimorphism in branch number may be used by horticulturists to inform decisions. Dioecious species offer choices to horticulturists that are not available for monoecious species. For example, if a property owner has a preference for an unbranched Cycas tree that appears more palm-like (Figure 1b), the new knowledge that a female tree will meet that preference more often than a male tree can be exploited. Conversely, when considering highly branching, shrub-like geophilous species of Zamia for landscape design, male plants may make more robust specimens with a higher number of branches, leaves and cones, as demonstrated with Z. integrifolia by Norstog and Nicholls [1] (p. 141). Shrub-like Zamia species are often used in landscape designs as stand-alone specimens or in mass plantings as foreground layers or hedges. This shrub-like habit can be found in several Zamia species throughout the geographic range of the genus [32] but is most common in Caribbean species such as Z. integrifolia, and Mexican species, such as Z. furfuracea, one of the most abundantly cultivated cycads in the world. Small basal stem cuttings of cycad plants are highly successful in producing adventitious roots [33-35]. This knowledge may be exploited to clonally propagate a female or a male tree to obtain the desired landscape objective.

Our results also inform conservation decisions. Cycads form the most threatened group of plants worldwide [3]. For example, C. wadei is listed as critically endangered [36], C. micronesica is listed as endangered [37], Z. encephalartoides is listed as vulnerable [38], and C. edentata is listed as near threatened [39]. Our repeated visits to numerous areas of occupancy for all four of our model species have documented extensive loss of habitat due to anthropogenic land conversion actions.

This is happening in Guam due to expansive construction projects, and federally funded rescue projects have employed the collection of cuttings or excavated transplants of $C$. micronesica to rescue some of the genetic diversity of the destroyed populations. Much has been learned about the capture of in situ genetic diversity while collecting for ex situ conservation of cycad species [40,41]. The collection of clones instead of seeds improves the conservation of genetic diversity in ex situ collections [42]. The pilot study for the Guam rescue projects [43] utilized the knowledge of branch differences to ensure $\approx 60 \%$ of the rescued trees were unbranched, $\approx 20 \%$ contained two apices, and $\approx 20 \%$ contained three or 
more apices as an approach that would ensure fairly equal representation of male and female trees in the rescued population. In contrast the most recent large-scale salvage project, which employed excavation and transplantation of mature trees, did not utilize this branching knowledge, as the rescued population was heavily represented by specimens with multiple apices (personal observation, T.E.M.). This oversight ensured that most of the rescued population would be male trees, thereby reducing future recruitment and regeneration potential of the restoration site in which the plants were transplanted. These case studies illuminate the need to ensure that appropriate species expertise is guiding the decisions in conservation projects, especially when public funding is involved. Indeed, that male cycad plants produce more stem apices than female plants has been known since the 1980s [12], so if a cycad biologist had been consulted in the conservation decisions of the transplant project this mistake would not have been made.

The use of stem branching traits to inform cycad conservation decisions adds to a growing body of evidence that illuminates the importance of including conservation practitioners with a verifiable understanding of plant behavior. Other plant traits that have been discussed for use in cycad conservation decisions included stem carbon dioxide efflux [44] and stem height increment [45].

\subsection{Future Directions}

The collective results point toward several areas of needed research. Continued work in these directions would contribute greatly to cycad biology and conservation.

First, long-term observational studies are needed to determine the branching behavior for many cycad species. Although we believe the higher number of branches found on male plants in this study is a consequence of isotomous branching associated with more frequent terminal cone production, this is based on indirect observations, and the relative contribution of adventitious vs. isotomous branching to the stem architecture of these and other cycad species remains obscure. Direct observations over time will provide the data needed to quantify the nature of branching on different cycad species and to better understand the process of stem bifurcations following coning events. The collective data to date include only two Zamia and three Cycas species, and little is known about the branching behavior of the remaining 358 species of cycads [46]. Clearly, observations from the other eight genera and more species are required to improve our understanding of branching processes in cycads, and botanic gardens are ideal settings for this demanding long-term endeavor.

Second, future research should explore the relationship between reproductive anisotomous branching and the isotomous vegetative branching that often follows it and attempt to understand the mechanisms underlying these phenomena. While we observed this in both sexes of Zamia, we only observed it on male Cycas plants. As female Cycas do not form terminal cones, this observation suggests that there may be a link between the ability of cycads to produce terminal cones via anisotomous branching and their ability to produce isotomous vegetative branches. A more detailed survey of female Cycas plants and the plants from the three genera that do not produce terminal cones (Encephalartos, Lepidozamia, and Macrozamia) may confirm whether this is the case. Additionally, anatomical studies are needed in order to understand the mechanism underlying isotomous vegetative branching following cone production. For example, it is unclear if this phenomenon could be the result of trichotomous branching where the apex divides into one fertile and two vegetative apices, or of two dichotomous branching events occurring in quick succession, or of some other unknown mechanism. Careful sectioning of cycad stems undergoing this process could help resolve this conundrum.

Third, our results indicating that the recent invasions of non-native insect herbivores have killed more unbranched trees than multi-branched trees in Guam deserve further study. The results indicate more female trees have been killed than male trees, which will exert negative consequences for species recovery if future conservation interventions become successful in mitigating the ubiquitous biological threats. This disparity in vulnerability to the biological threats is likely mediated by non-structural carbohydrate relations. The greatest threat to the $C$. micronesica plants has been the armored scale Aulacaspis yasumatsui Takagi, and plant mortality from this herbivore is preceded by a gradual 
depletion of plant non-structural carbohydrates [47]. Cumulative traditional knowledge that guides the exploitation of cycad stems for the production of starch for human consumption indicates male stems yield more starch than female stems [48]. These issues collectively indicate the limited pool of non-structural carbohydrates in female trees at the time of the insect invasions may have caused the female trees to be more vulnerable than the male trees. Further studies of stem non-structural carbohydrate relations in male and female trees may improve our understanding of these historical dynamics and inform future conservation decisions for species recovery.

Fourth, illuminating clarity of how subsets of plants inform these issues may improve the predictive usage of the information in horticulture. For example, our three Cycas arborescent species exhibited less difference in total number of branches between male and female plants than the Zamia species with partly subterranean stems. Do the male-female differences in branching behave differently based on life form, rather than based on taxonomy, such that the arborescent species as a group behave differently than the subterranean species as a group? Moreover, most of our female Cycas individuals were unbranched. Do the indeterminate traits of $C y c a s$ megastrobili versus the determinate traits of the megastrobili of the other arborescent genera fully explain the increased proportion of monopodial Cycas individuals? For arborescent species, tree height increases with the number of primary growth events which accumulate with age [1]. Does tree height correlate positively with the number of branches for all species?

\section{Conclusions}

We have added more empirical evidence to earlier reports of sexual dimorphism that indicate male cycad plants produce more branches than female plants. Collectively, three Cycas species and two Zamia species have confirmed this aspect of secondary sexual behavior of the Cycadales. The changes in proportion of branched versus unbranched C. micronesica trees in Guam between 2004 and 2020 indicates that more female trees have died due to the damage from non-native insect herbivores that began in 2005. Horticulturists may exploit this knowledge of branching to increase the likelihood of achieving near equal numbers male and female plants during conservation rescue projects.

Author Contributions: Conceptualization, T.E.M. and M.C.; methodology, T.E.M. and M.C.; formal analysis, T.E.M.; resources, T.E.M. and M.C.; writing—original draft preparation, T.E.M.; writing—review and editing, M.C.; project administration, T.E.M. and M.C.; funding acquisition, T.E.M. and M.C. All authors have read and agreed to the published version of the manuscript.

Funding: This research was funded by the United States Department of Agriculture grant numbers 2003-05495 and 2013-31100-06057, the United States Forest Service grant numbers 09-DG-11052021-173, 13-DG-11052021-210, and 17-DG-11052021-217, and the Conservation Leadership Programme's Future Conservationist Award (project ID 130609).

Acknowledgments: We thank Nirmala Dongol, Gil Cruz, Frankie Matanane, and Michell Mooy for technical support.

Conflicts of Interest: The authors declare no conflict of interest.

\section{References}

1. Norstog, K.J.; Nicholls, T.J. The Biology of the Cycads; Cornell University Press: Ithaca, NY, USA, 1997; ISBN 978-0-8014-3033-6.

2. Whitelock, L.M. The Cycads; Timber Press: Portland, OR, USA, 2002.

3. Fragniere, Y.; Bétrisey, S.; Cardinaux, L.; Stoffel, M.; Kozlowski, G. Fighting their last stand? A global analysis of the distribution and conservation status of gymnosperms. J. Biogeogr. 2015, 42, 809-820. [CrossRef]

4. Convention on International Trade in Endangered Species of Wild Fauna and Flora. The CITES Species. Available online: https://www.cites.org/eng/disc/species.php (accessed on 8 October 2020).

5. Rutherford, C.; Donaldson, J.; Hudson, A.; McGough, H.N.; Sajeva, M.; Schippmann, U.; Tse-Laurence, M. CITES and Cycads: A User's Guide; Kew Publishing, Royal Botanic Gardens: Kew, UK, 2013.

6. Marler, T.E. Horticultural research crucial for plant conservation and ecosystem restoration. HortScience 2017, 52, 1648-1649. [CrossRef] 
7. Marler, T.E.; Lindström, A.J. The value of research to selling the conservation of threatened species: The case of Cycas micronesica. J. Threat. Taxa 2014, 6, 6523-6528. [CrossRef]

8. Clark, D.A.; Clark, D.B. Temporal and environmental patterns of reproduction in Zamia skinneri, at tropical rain forest cycads. J. Ecol. 1987, 75, 135-149. [CrossRef]

9. Lazcano-Lara, J.C.; Ackerman, J.D. Best in the company of nearby males: Female success in the threatened cycad, Zamia portoricensis. PeerJ 2018, 6, e5252. [CrossRef]

10. Calonje, C.; Calonje, M.A.; Husby, C.E. Cycad sex ratios at Montgomery Botanical Center. Mem. N. Y. Bot. Garden 2018, 117, 360-370.

11. Lloyd, D.G.; Webb, C.J. Secondary sex characteristics in seed plants. Bot. Rev. 1977, 43, 177-216. [CrossRef]

12. Ornduff, R. Gender performance in a cultivated cohort of the cycad Zamia integrifolia (Zamiaceae). Am. J. Bot. 1996, 83, 1006-1015. [CrossRef]

13. Niklas, K.J.; Marler, T.E. Sex and population differences in allometry of an endangered cycad species, Cycas micronesica (Cycadales). Int. J. Plant Sci. 2008, 169, 659-665. [CrossRef]

14. Marler, T.E.; Krishnapillai, M.V. Longitude, forest fragmentation, and plant size influence Cycas micronesica mortality following island insect invasions. Diversity 2020, 12, 194. [CrossRef]

15. Calonje, M.; López-Gallego, C. Cycad conservation: Zamia encephalartoides in Colombia. Montgomery Bot. News 2011, 19, 4.

16. Dongol, N.; Marler, T.E. Season and frequency of Cycas micronesica leaf and reproductive events. Mem. N. Y. Bot. Gard. 2018, 117, 497-503.

17. Stevenson, D.W. Observations on vegetative branching in cycads. Int. J. Plant Sci. 2020, 181, 564-580. [CrossRef]

18. Singh, R.; Radha, P. A new species of Cycas from Karnataka, India. Bot. J. Linnaean Soc. 2008, 158, 430-435. [CrossRef]

19. Gorelick, R. Isotomous branching at the Zamia furfuracea cone axis. Cycad Newsl. 2011, 34, 29.

20. Stevenson, D.W. A formal classification of the extant cycads. Brittonia 1992, 44, 220-223. [CrossRef]

21. Salas-Leiva, D.E.; Meerow, A.W.; Calonje, M.; Griffith, M.P.; Francisco-Ortega, J.; Nakamura, K.; Stevenson, D.W.; Lewis, C.E.; Namoff, S. Phylogeny of the cycads based on multiple single-copy nuclear genes: Congruence of concatenated parsimony, likelihood and species tree inference methods. Ann. Bot. 2013, 112, 1263-1278. [CrossRef]

22. Norstog, K. Cycadophyte. Encyclopedia Britanica. 2017. Available online: https://www.britannica.com/ plant/cycadophyte (accessed on 8 October 2020).

23. Stevenson, D.W. Strobilar ontogeny in the Cycadales. In Aspects of Floral Development; Leins, S., Tucker, S.C., Endress, P.K., Eds.; Cramer: Berlin, Germany, 1988; pp. 205-224.

24. Stevenson, D.W. Morphology and systematics of the Cycadales. Mem. N. Y. Bot. Gard. 1990, 57, 8-55.

25. Marler, T.E. Pacific island tropical cyclones are more frequent and globally relevant, yet less studied. Front. Environ. Sci. 2014, 2, 42. [CrossRef]

26. Marler, T.E. Tropical cyclones and perennial species in the Mariana Islands. Hortscience 2001, 36, $264-268$. [CrossRef]

27. Marler, T.E.; Hirsh, H. Guam's Cycas micronesica population ravaged by Supertyphoon Paka. HortScience 1998, 33, 1116-1118. [CrossRef]

28. Marler, T.E.; Lawrence, J.H. Phytophagous insects reduce cycad resistance to tropical cyclone winds and impair storm recovery. HortScience 2013, 48, 1224-1226. [CrossRef]

29. Hirsh, H.T.; Marler, T. Damage and recovery of Cycas micronesica after Typhoon Paka. Biotropica 2002, 34, 598-602. [CrossRef]

30. Marler, T.E. Increased threat of island endemic tree's extirpation via invasion-induced decline of intrinsic resistance to recurring tropical cyclones. Communic. Integr. Biol. 2013, 6, e22361. [CrossRef] [PubMed]

31. Marler, T.E.; Lawrence, J.H.; Cruz, G.N. Topographic relief, wind direction, and conservation management decisions influence Cycas micronesica K.D. Hill population damage during tropical cyclone. J. Geogr. Nat. Disasters 2016, 6, 3. [CrossRef]

32. Calonje, M.; Meerow, A.W.; Griffith, M.P.; Salas-Leiva, D.; Vovides, A.P.; Coiro, M.; Francisco-Ortega, J. A time-calibrated species tree phylogeny of the New World cycad genus Zamia, L. (Zamiaceae, Cycadales). Int. J. Plant Sci. 2019, 180, 286-314. [CrossRef] 
33. Deloso, B.E.; Lindström, A.J.; Camacho, F.A.; Marler, T.E. Highly successful adventitious root formation of Zamia stem cuttings exhibits minimal response to indole-3-butyric acid. HortScience 2020, 55, 1463-1467. [CrossRef]

34. Deloso, B.E.; Paulino, C.J.; Marler, T.E. Leaf retention on stem cuttings of two Zamia, L. species with or without anti-transpirants does not improve adventitious root formation. Trop. Conserv. Sci. 2020, 13. [CrossRef]

35. Marler, T.E.; Deloso, B.E.; Cruz, G.N. Prophylactic treatments of Cycas stem wounds influence vegetative propagation. Trop. Conserv. Sci. 2020, 13, 1-6. [CrossRef]

36. Hill, K.D. Cycas wadei. The IUCN Red List of Threatened Species 2010: E.T42097A10631294. 2010. Available online: https://www.iucnredlist.org/species/42097/10631294 (accessed on 8 October 2020). [CrossRef]

37. Marler, T.; Haynes, J.; Lindstrom, A. Cycas micronesica. The IUCN Red List of Threatened Species 2010: E.T61316A12462113. 2010. Available online: https://www.iucnredlist.org/species/61316/12462113 (accessed on 8 October 2020). [CrossRef]

38. Stevenson, D.W. Zamia encephalartoides. The IUCN Red List of Threatened Species 2010: E.T42151A10668503. 2010. Available online: https://www.iucnredlist.org/species/42151/10668503 (accessed on 8 October 2020). [CrossRef]

39. Osborne, R.; Hill, K.D.; Nguyen, H.T.; Phan, K.L. Cycas edentata. The IUCN Red List of Threatened Species 2010: E.T42091A10628022. 2010. Available online: https://www.iucnredlist.org/species/42091/10628022 (accessed on 8 October 2020). [CrossRef]

40. Griffith, M.P.; Calonje, M.; Meerow, A.W.; Tut, F.; Kramer, A.T.; Hird, A.; Magellan, T.M.; Husby, C.E. Can a botanic garden cycad collection capture the genetic diversity in a wild population? Int. J. Plant Sci. 2015, 176, 1-10. [CrossRef]

41. Griffith, M.P.; Calonje, M.; Meerow, A.W.; Francisco-Ortega, J.; Knowles, L.; Aguilar, R.; Tut, F.; Sánchez, V.; Meyer, A.; Noblick, L.R.; et al. Will the same ex situ protocols give similar results for closely related species? Biodivers. Conserv. 2017, 26, 2951-2966. [CrossRef]

42. Griffith, M.P.; Clase, T.; Toribio, P.; Piñeyro, Y.E.; Jimenez, F.; Gratacos, X.; Sanchez, V.; Meerow, A.; Meyer, A.; Kramer, A.; et al. Can a botanic garden metacollection better conserve wild plant diversity? A case study comparing pooled collections with an ideal sampling model. Int. J. Plant Sci. 2020, 181, 485-496. [CrossRef]

43. Marler, T.E.; Cruz, G.N. Adventitious rooting of mature Cycas micronesica K.D. Hill tree stems reveals moderate success for salvage of an endangered cycad. J. Threat. Taxa 2017, 9, 10565-10570. [CrossRef]

44. Marler, T.E. Stem $\mathrm{CO}_{2}$ efflux of Cycas micronesica is reduced by chronic non-native insect herbivory. Plant Signal. Behav. 2020, 15, e1716160. [CrossRef]

45. Marler, T.E.; Griffith, M.P.; Krishnapillai, M.V. Height increment of Cycas micronesica informs conservation decisions. Plant Signal. Behav. 2020, 15, e1830237. [CrossRef]

46. Calonje, M.; Stevenson, D.W.; Osborne, R. The World List of Cycads. Available online: http://cycadlist.org (accessed on 8 October 2020).

47. Marler, T.E.; Cascasan, A.N.J. Carbohydrate depletion during lethal infestation of Aulacaspis yasumatsui on Cycas revoluta. Int. J. Plant Sci. 2018, 179, 497-504. [CrossRef]

48. Whiting, M.G. Toxicity of cycads, a literature review. Econ. Bot. 1963, 17, 270-302. [CrossRef]

(C) 2020 by the authors. Licensee MDPI, Basel, Switzerland. This article is an open access article distributed under the terms and conditions of the Creative Commons Attribution (CC BY) license (http://creativecommons.org/licenses/by/4.0/). 